\title{
The effect of positive youth project to improve optimism in students
}

\author{
Nur Afni Indahari \\ Department of Psychology \\ State University of Makassar \\ Indonesia \\ afni_arifin@yahoo.co.id
}

\author{
Wawan Kurniawan \\ Department of Psychology \\ State University of Makassar \\ Indonesia
}

\begin{abstract}
Optimism is a form of consideration that has a tendency to affect the feelings, attitudes and behavior of a person in certain situations. Optimism is an association created by leading to the safety of positive outcomes and be able to moderate the relationship between the perceived stress to be better. Youth have many challenges, that can lower their optimism. Positive Youth Project (PYP) is an annual event of the Indonesian Psychological Association (HIMPSI) South Sulawesi for student at aged 15-18 years. The purpose of this study was to determine the effect of optimism PYP against the participants. These research subjects are participants from various SMA / MA / SMK who have passed the selection in these activities. This research method using quasi experimental, pre-posttest design. Results were pointing there is an influence on the participants after following the Positive Youth Project activities. This proves that one of the effect of Positive Youth Program is increasing the optimism of participants.
\end{abstract}

Keywords-optimism; students; positive youth project

\section{INTRODUCTION}

Optimism is a unity that was created with a lock on security, which is an overall optimism, is much better than pessimism [1]. Thompson \& Gaudreau stated that the optimism as intermediaries in encouraging motivation to achieve positive things, which can be a task in education. Optimism is positively correlated with the process of overcoming approaches, positive tasks, but negatively correlated with avoidance [2].

Based on the study of research conducted by Chang, it was found that optimism moderated the relationship between stress and psychological adjustment measures, optimism is also moderated by the association between stress life and global life satisfaction [1]. Yates reveals a study that determined the differences between optimists and pessimists in the explanation of attribution include the important aspects of adjustment and affecting health, motivation and learning [3].

Optimism of the individual will be supported by the presence of better self-leadership [4]. One of the problems youth facing today is the lack of space to develop themselves, so the potential can be maximized.

Young people or students need positive things in shaping their own development. Youths who have weak characters will have problems with social conditions, such as brawling and drug abuse. Cognitively the youth have idealistic ideas that are unlike children and the disguised models show ideal characters and imitate interesting models that are young, enchanting, and successful [5]. The condition of high school students / MA / SMK become something interesting to be studied in this research.

Scheier and Carve reveals that every human being is different from each other about approaching the world, optimism is one way of approaching a world that is generally believed to lead to good things rather than bad things they will get [6]. Optimism is also regarded as a way that tends to anticipate getting bad results. Through Positive Youth Project (PYP) program, researchers try to see the optimism of the participants. In this program, participants are invited to design activities and run what has been discussed during the activity. It is expected that the participants can be optimistic and successfully run the plan.

\section{METHOD}

\section{A. Participants}

The subjects of this study were students from various regions who were following Positive Youth Project 2017. The total subject were 32 participants obtained from PYP Program organized by the Indonesian Psychological Association (HIMPSI) of South Sulawesi.

\section{B. Intervention}

This research method used quasi experimental design, The One Group Pretest-Posttest. The Positive Youth Project gave participants the opportunity to receive information such as, Who Am I? Social Contributions, Alumni Sharing Session, Leader: Sharing and Happy, Inspiration from Perahu Pustaka, games and outbound at the end of the activities.

\section{RESULT}

In this study, there were 32 participants aged 15 to 18 years old. The result of post-test statistical analysis on optimistic variable is seen in the following table. 
TABLE I. PRE- AND POSTTEST ON OPTIMISM

\begin{tabular}{llll}
\hline & & Mean & Sum \\
\hline Optimism & Pre-Test & 31,83 & 1018,50 \\
\hline & $\begin{array}{c}\text { Post- } \\
\text { Test }\end{array}$ & 33,17 & 1061,50 \\
\hline
\end{tabular}

The Table I. shows that there is an increase of optimistic average when compared between pre-test $(X=31,83)$ with post-test $(X=33,17)$. Furthermore, due to the non-random sampling technique, the hypothesis test used in this study is non-parametric statistics.

TABLE II. MANN-WHITNEY TEST ON OPTIMISM

\begin{tabular}{ll}
\hline & Optimism \\
\hline Mann-Whitney U & 490,500 \\
\hline Wilcoxon W & 1018,500 \\
\hline $\mathrm{Z}$ & $-2,292$ \\
\hline Asymp. Sig. (2-tailed) &, 770
\end{tabular}

Based on Table II, it is seen that the average optimistic value in posttest (33.17) is greater than the average in pretest (31.83). This value shows that there are optimistic optimist differences in pre- and posttest.

U Mann Whitney test results proved a significant result because $(p<0.05)$. Hence, the hypothesis $\mathrm{H} 1$ is accepted. It means that there is a significantly optimistic increase in participants before and after Positive Youth Project.

\section{DISCUSSION}

In this study, the results obtained from the training provided significant results. Participants in Positive Youth Project activities are asked to perform the program which is the result of discussion. The various materials that have been received help participants to know and learn to be more optimistic. According Karley, optimism is the explanatory style (how we explain something to ourselves), and also an attitude (how do we feel something). It is a behavioral component that produces a complex outcome of one's thoughts and emotions [7].

Seligman [6] also explained that the way individuals perceive an event in their life is closely related to the individual style in explaining an event (explanatory style). In this activity, the participants are shown some experiences from some people who have done social activities. Activities that will also be expected to be replicated and require optimism in running it.

In the process optimism of the individual will be supported by the development of better self-leadership. In optimistic individuals, they will develop self-leadership and with it, the planned program works well [4].

\section{ACKNOWLEDGMENT}

This study was financed by PNBP grant Psychology Faculty, State University of Makassar and carried out in cooperation with and facilitation by HIMPSI Chapter South Sulawesi.

\section{REFERENCES}

[1] E.C. Chang." Does dispositional optimism moderate the relation between perceived stress and psychological well-being: a preliminary investigation".Personality and Individual Differences Vol. 25, 233-240, 1998

[2] A. Thompson \& P. Gaudreau. "From Optimism and Pessimism to Coping: The Mediating Role of Academic Motivation”. International Journal of Stress Management, Vol. 15, No.3, pp 269-288, 2008.

[3] S.M. Yates. "The influence of optimism and pessimism on student achievement in mathematics". Mathematics Eduation Journal Research. Vol 14, No.1, pp 4 -15, 2002.

[4] C.L. Dolbier, M. Soderstrom, M.A. Steinhardt. "The relationships between self-leadership and enhanced psychological, health, and work outcomes". The Journal of Psychology, Vol. 135, No. 5, pp 469- 485, 2001.

[5] E.B Hurlock. Psikologi Perkembangan. Jakarta: PT. Erlangga, 1993.

[6] M. F. Scheier \& C. S. Carver. "Optimism, Coping, and Health: Assessment and Implications of Generalized Outcome Expectancies." Health Psychology, Vol.4., No.3, pp 219-247, 1985

[7] D.C. Kerley. "The Optimist". Licensed Psychologist, Vol.1, No.1, 2006.

[8] M. E. Seligman (Ed.). The Optimistic Child: A Proven Program to Safeguard Children Against Depression and Build Lifelong Resistance. Harper Perennial. 1995. 